\title{
The Study of Some Potential Risk factors Associated with Coccidiosis (Eimeria) in Sheep in Kashmir Valley
}

\author{
Altaf Ahmad Reshi and Hidayatullah Tak \\ Dept. of Zoology, University of Kashmir, Hazartbal, Srinagar 1900 06, J\&K, India
}

\begin{abstract}
The present study was carried out from October 2011- September 2012 to study the potential risk factors associated with the coccidiosis in sheep in Kashmir valley. The risk factors under study were Breed, Feeding system, Watering system, Housing pattern, floor type, and Flock size. A total of 192 samples were examined for the infection. During the study it was found that a total of 54.68\% samples were infected with coccidian Oocysts. Non local (exotic) breed of sheep was found to have higher percentage prevalence of coccidiosis being 68.18\% than local breed being 36.5\%. More infection was found in sheep of larger flock size and reared on the non-cemented floor pattern with stastically significant difference. Similarly more infection was found in sheep having ground pattern of feeding and given stream water but the data was stastically non significant. However Housing pattern of the animals had no impact on the prevalence of the disease.
\end{abstract}

Key Words: Coccidiosis; Prevalence; sheep; Kashmir; Risk factors.

\section{Introduction}

Coccidiosis is worldwide distributed disease and one of the most economically important infections threatening the Animal industry. Coccidia are microscopic, spore - forming, obligate, and intracellular parasites. These species cause pathological damage and mortality in poultry, cattle, sheep, goats, pig, rabbit and other animals. Ovine coccidiosis is one of the most common causes of enteritis in sheep. Its economic importance is attributed to the reduction of body weight; inefficient feed utilization and death of severely affected animals. Because of these reason coccidia have attracted the attention of many workers. The present study was aimed to study the effect of potential risk factors viz., Breed, feeding system, watering system, Housing pattern, floor type, and flock size on the prevalence of coccidiosis in sheep in Kashmir Valley.

\section{Material And Methodology:}

Fresh faecal samples of 192 sheep of different age groups were collected from local farmers rearing sheep in different parts of Kashmir valley throughout one year. The samples were collected in plastic containers containing $4 \%$ formalin and brought to parasitological lab. Both sedimentation method (Charles and Josphine, 1970) and floating technique (Charles and Josphine, 1970; Soulsby, 1982) were used to detect the presence of Oocysts. Suspension of each faecal sample was strained through muslin cloth and examined under light microscope.

\section{Development of Questionnaire:}

A questionnaire was developed for collecting necessary information from farmers regarding associated risk factors. Information regarding following determinants were collected through questionere.

Breed: Local and Exotic breeds were under study.

Husbandry and Management: Type of Feeding System (Grazing/Ground feeding, Trough Feeding and Mixed), Housing System (Open/Close), Floor Pattern (Cemented/Non- Cemented), Watering System (Tap, Stream/lake/pond and Mixed) and Herd size (Larger/Smaller) were observed in the present study. Herds having more than fifty animals were declared as larger whereas herds with less than this were considered as smaller.

\section{Results:}

In the present study a total of 192 faecal samples of sheep were examined for a period one year from October 2011 to September 2012. The overall prevalence of coccidiosis was 54.68\%. Prevalence of Coccidiosis was different in local and exotic breeds of sheep being $36.58 \%$ in local and $68.18 \%$ in exotic breed, $(\mathrm{P}=0.000)$ which means data is statistically highly significant $(\mathrm{P}<0.05)$ (Table 1). Although prevalence of coccidiosis in sheep ( grazing/ ground feeding $=57.57 \%$; trough feeding $=43.33 \%$, mixed $=56.25 \%$ ) fed under three feeding systems was different being highest in ground feeding sheep, followed in order by mixed feeding (both trough and ground feeding ) and least in trough feeding sheep but statistically insignificant association was found with $\mathrm{P}=0.391$ (Table 2). An insignificant association $(\mathrm{P}=0.591)$ was observed between housing system and risk of coccidian infection (Table 3). Statistically different rate of prevalence was found in two floor types. Coccidian 
infection was more prevalent $(\mathrm{P}<0.05)$ in non-cemented floor type $(45.12 \% ; 37 / 82 ; \mathrm{P}=0.022)$ as compared to cemented floor (Table 4). Multivariate logistic regression analysis and M.H. Chi-Square analysis of watering system with the intensity of infection revealed that there was insignificant association between these two $(\mathrm{P}=0.08)$ (Table 5). Prevalence of coccidiosis was strongly predisposed by the herd size $(\mathrm{P}<0.05)$. Higher prevalence was observed in larger herds $(64 \% ; 64 / 100 ; \mathrm{P}=0.007)$ as compared to smaller ones $(44.5 \% ; 41 / 92)$ (Table 6).

\begin{tabular}{|l|l|l|l|l|}
\hline Table 1. Prevalence of coccidiosis in different Breeds & P-value \\
\hline Breed & Observed & Infected & Prevalence & \\
\cline { 1 - 4 } Local & 82 & 30 & $36.5 \%$ & \\
\cline { 1 - 3 } Non-Local & 110 & 75 & $68.18 \%$ & \\
\hline Total & 192 & 105 & & \\
\hline
\end{tabular}

\begin{tabular}{|l|l|l|l|l|}
\hline \multicolumn{5}{|l|}{ Table 2. Prevalence of coccidiosis with respect to Feeding System of Animals } \\
\cline { 1 - 4 } Type of Feeding System & Observed & Infected & Prevalence & \multirow{2}{*}{0.391} \\
\cline { 1 - 4 } Ground/Grazing & 66 & 38 & $43.37 \%$ & \\
\hline Trough & 30 & 54 & $56.25 \%$ & \\
\hline Mixed & 96 & $54 \%$ & & \\
\hline
\end{tabular}

\begin{tabular}{|l|l|l|l|l|}
\hline \multicolumn{4}{|l|}{ Table 3. Prevalence of coccidiosis with respect to Housing Structure of Animals } & Prevalence \\
\hline Housing Structure & Observed & Infected & $52.22 \%$ & P-value \\
\hline Closed & 90 & 47 & $56.86 \%$ & 0.591 \\
\hline Open & 102 & 58 & & \\
\hline Total & 292 & 105 & \\
\hline
\end{tabular}

\begin{tabular}{|l|l|l|l|l|}
\hline \multicolumn{4}{|l|}{ Table 4. Prevalence of coccidiosis with respect to Floor Pattern of Animals } & P-value \\
\hline Floor Pattern & Observed & Infected & Prevalence & \\
\cline { 1 - 4 } Cemented & 82 & 37 & $45.12 \%$ & $61.81 \%$ \\
\hline Non-Cemented & 110 & 68 & & \\
\hline Total & 192 & 105 & & \\
\hline
\end{tabular}

\begin{tabular}{|l|l|l|l|l|}
\hline \multicolumn{5}{|l|}{ Table 5. Prevalence of coccidiosis with respect to Watering System of Animals } \\
\cline { 1 - 3 } Watering System & Observed & Infected & Prevalence & \multirow{2}{*}{0.08} \\
\hline Tap & 30 & 11 & $36.66 \%$ & \\
\hline Stream & 106 & 62 & $58.49 \%$ & \\
\hline Mixed & 56 & 32 & $57.14 \%$ & \\
\hline
\end{tabular}

\begin{tabular}{|l|l|l|l|l|}
\hline Table 6. Prevalence of coccidiosis with respect to Herd Size of Animals & \multicolumn{2}{l|}{ P- value } \\
\hline Herd Size & Observed & Infected & Prevalence & \multirow{2}{*}{0.007} \\
\hline Large & 100 & 64 & $64 \%$ & \\
\hline Small & 92 & 41 & $44.5 \%$ & \\
\hline Total & 192 & 105 & & \\
\hline
\end{tabular}

\section{Discussion:}

In the present study, Breed was found to have a significant impact on the prevalence of coccidiosis as higher rate of infection was recorded in exotic breed than in local breed. Same results were also recorded by khan et al., 2008 who reported higher prevalence of coccidiosis in Corrie dale (exotic to Kashmir valley) breed. The prevalence was recorded lowest in local Kashmiri breed and the prevalence in crossbred Kashmiri Merino breed was found intermediate. The differences in the percentage prevalence of this infection among different breeds of sheep are also in agreement with the earlier observations, where some breeds were found to be more infected by parasitism than others (Wildeus and Zajac, 2005), Li et al. (2001) in the Gulf Coast region of US also found native Breed more resistant to coccidiosis infection than Suffolk breed. The difference could be attributed to the fact that non-local sheep in Kashmir come from areas like Rajasthan and some parts Jammu region having hot and humid climate which is conducive for the sporulation of the coccidian oocysts. Higher prevalence rate was recorded in grazing/ground feeding animals than trough feeding which is in line with the observations made by Ahmed et al. (1992) and Singha (1992). However Khan et al (2011) reported more prevalence in trough feeding animals than grazing ones which is not in agreement with the present study. The difference could be attributed to the fact that during late spring, summer and early autumn season's sheep feed in open pasture in large flocks and defecate in the same grazing feild thereby enhancing the chances of transmission of the infection. Moreover crowding in grazing pastures also facilitates contamination and transmission of coccidia (Deb et al. 1982). The housing condition of the animals was not seen to have a significant impact on the prevalence of the disease. The observed results are not in line with the earlier observation of Khan et al. (2011) who recorded a higher prevalence in closed housed condition. The disparity could be attributed to the fact that in the study area a usual habit of people is allowing sheep to graze in open during day and are confined to closed houses during night and therefore animals are neither permanently 
confined to open nor to closed housed condition, thus same animals share both types of housing conditions at a particular period and rendering all of them equally vulnerable for the development of the disease. But the other factors like floor type, watering system and flock size had a significant impact on prevalence of the disease. Higher prevalence rate was observed in non cemented floor than in cemented floor and same pattern of incidence was reported by Khan et al (2011) who observed more prevalence in non cemented floor ( $\mathrm{p}<0.05$, $\left.48.5 \%, \chi^{2}=10.705\right)$ as compared to cemented floor. Iqbal and Sajid (2008) also found that Coccidiosis was more prevalent in non-cemented floor type and larger herds $(\mathrm{P}<0.05)$ as compared to closed housing system, partially cemented floor type and smaller herds respectively. The disparity could emanate from the fact that In the non cemented floor type urine accumulates in the floor and increases the temperature; thereby providing warm and wet environment favourable for the sporulation of the Oocysts, moreover higher prevalence of coccidiosis in non cemented (mud/ mud+brick) type of floor may be associated with more chances of coccidian Oocysts to survive in cracks and crevices of mud/ mud +brick type of floor which may be difficult for effective cleanliness of houses ( Lawrence 2011). Higher prevalence was observed in sheep watered at stream/pond compared to those given tap water. However the animals having a mixed type of watering system (sometimes tap water, sometimes pond/lake or stream water whatever available) were also found to have relatively higher percentage prevalence of coccidiosis than the animals given only tap water. The results are in commensuration with khan et al. (2011) who observed a higher prevalence in sheep, $48.98 \%$., as compared to those given only tap water. The disparity could emanate from the fact that while watering at pond or lake animals usually defecate in or near the same water source thereby increasing the chances of contamination with coccidian oocysts. Similarly higher prevalence was found in sheep of larger flock size than of smaller ones. The observed results are in line with Khan et al., (2011), Iqbal and Sajid ( 2008) who observed higher prevalence of coccidiosis in larger herds of sheep $\left(52.73 \%, \chi^{2}=15.47\right)$ as compared to smaller ones $(34.96 \%)$. Similar pattern of results were observed by Roger et al (1996) in calves which may be correlated with the mixed rearing facts of small and large ruminants. The disparity could be related with the fact that animals in large herds are in overcrowded condition and will be more likely to ingest large number of sporulated coccidian Oocysts over a short period of time (Rodriguez, 1980). Moreover crowding also facilitates contamination and transmission of coccidia (Deb et al. 1982).

\section{References}

[1]. Ahmed, M. I., Umoh, J. U. and Brisibe, F. 1992. Risk factors of ovine and caprine Coccidiosis in an arid zone of Nigeria. Indian Veterinary Medical Journal, 16(4): 274-278.

[2]. Deb, A. R., Sinha, B. N., Sahai, B. N. and Ansari, M. Z. 1981a. Studies on histopathology and histochemistry of experimental coccidiosis in Black Bengal goats. Indian Journal of Animal Health, 21: 33-38

[3]. Deb, A. R., Sinha, B. N., Sahai, B. N. and Ansari, M. Z. 1981b. Efficacy of Amprolium, Sulphamezathine and Sulmet against coccidiosis in goats. Indian Veterinary Journal, 58: 689-691

[4]. Lawrence, S. (2011). The prevalence of coccidiosis of chicken in Kalisizo Town Council, Rakai District, Uganda.

[5]. Liy, JE Miller and DE Franke, 2001. Epidemiology, observation and hetrosis analysis of gastrointestinal nematode parasitism in Suffolk, Gulf Coat Native and cross-bred lambs. Vet Parasitol, 98 : 273-282.

[6]. M. N. Khan, T. Rehman, Z. Iqbal, M. S. Sajid, M. Ahmad, M. Raaz, 2011. Prevalence \& Associated risk factors of Eimeria in sheep of Punjab, Pakistan. World academy of science, Engineering \& Technology 55).

[7]. Rodriguez ON. Distribucion de la coccidiosis en relacion con la edad de los terneros. Rev Salud Animal 1980; 2: 47-50.

[8]. Wildeus S and AM Zajac, 2005. Gastrointestinal parasitism in hair sheep and meat goat breeds grazing naturally infected pasture. Sheep Goat Res. J, 20: 42-46. 